Revista de la red interuniversitaria de estudios sobre las literaturas rioplatenses contemporáneas en Francia

\title{
Leandro Delgado: el escritor actor (ficción, posficción y después)
}

Leandro Delgado: l'auteur-comédien (fiction, postfiction et après)

Leandro Delgado: the actor writer (fiction, posfiction and after)

\section{Oscar Brando}

\section{(2) OpenEdition}

\section{Journals}

Electronic version

URL: http://journals.openedition.org/lirico/8315

DOI: 10.4000/lirico.8315

ISSN: 2262-8339

\section{Publisher}

Réseau interuniversitaire d'étude des littératures contemporaines du Río de la Plata

Electronic reference

Oscar Brando, «Leandro Delgado: el escritor actor (ficción, posficción y después) », Cuadernos LIRICO

[En línea], 20 | 2019, Publicado el 01 julio 2019, consultado el 02 junio 2020. URL : http://

journals.openedition.org/lirico/8315; DOI : https://doi.org/10.4000/lirico.8315

This text was automatically generated on 2 June 2020 .

\section{(c) $(1) \odot$}

Cuadernos LIRICO está distribuido bajo una Licencia Creative Commons Atribución-NoComercial-

SinDerivar 4.0 Internacional. 


\title{
Leandro Delgado: el escritor actor (ficción, posficción y después)
}

\author{
Leandro Delgado: l'auteur-comédien (fiction, postfiction et après) \\ Leandro Delgado: the actor writer (fiction, posfiction and after)
}

\section{Oscar Brando}
No me considero escritor a esta altura, no soy tan bueno ni tan malo para eso. Pero la idea de performer me gusta, de la transformación súbita de ese autor (de la idea de ese autor) según las circunstancias ficcionales, que al tiempo que yo
las defino, me definen y me niegan alternativamente. Como que escribiendo me
siento actor.
L.D. (comunicación personal por correo electrónico el 27/11/2018)

\section{Teoría}

1 Algo inevitable y melancólico acontece con la crítica literaria o, para decirlo con mayor precisión, con el uso que a lo largo de los años hacemos de la teoría para aplicarla a la crítica de textos y obras. Tal vez la cuestión no pase de un planteo simple. o bien pensamos que todo lo resolvió Aristóteles: lo que escribió en la estela de Platón, lo que agregó a las insuficiencias de su antecesor $y$, aun, lo que no pudo escribir porque su tiempo no se lo permitió; o bien buscamos escapes y nuevos deslindes, sin ignorar el círculo peripatético que parece encerrarlo todo. La palabra deslinde no se pone sin intención; quisiéramos señalar, a esta altura de la historia, la distancia que nos separa de la voluntad de Alfonso Reyes, hacia 1940, de deslindar el objeto literario de los demás objetos teóricos del espíritu. Así presentaba, en 1943, Martín Luis Guzmán el empeño de Reyes para sus conferencias en el Colegio Nacional, de las que saldrían unos "Prolegómenos a la teoría literaria": "El fenómeno literario lo había preocupado 
siempre: lo primero que anheló fue comprobar si había una visión de conjunto sobre el sentido humano de ese fenómeno" (Reyes 1963: 7). De estos esfuerzos tomaría forma el libro que publicó en 1944 y que, bajo el epígrafe de Kant: "No es engrandecer, sino desfigurar las ciencias, el confundir sus límites", tituló El deslinde.

2 No era Reyes, de hacerle caso a Rafael Gutiérrez Girardot en sus ensayos sobre el mexicano, el mejor ejemplo, como artista, de la ruta que proponía el pensamiento kantiano. Según el crítico colombiano, Reyes tendía a "promiscuar" en literatura, de donde el deslinde planteado por Kant y seguido en sus afanes teóricos resultaba más bien las antípodas (y tal vez una especie de antídoto) de la praxis creadora. Remontemos hasta ese cercano antecedente algunas de las paradojas que la literatura nos plantea y que, en forma de preguntas seriadas, dirían: ¿es la teoría literaria una ciencia? ¿Se constituye su espacio en el deslinde con otras ciencias? ¿Permite, su constitución, el reconocimiento de objetos específicos a los que llamamos literarios? ¿No es su esclarecimiento la luz necesaria para determinar los desajustes? ¿No son precisamente estos desajustes los que dan "sentido humano" a lo literario? Bref: qu'estce que la littérature?

\section{La ficción, una solución provisoria}

3 Citar a Jacques Rancière está un poco de moda, como lo estuvo, hasta no hace tanto, hacerlo con Benjamin, Deleuze, Agamben. Rancière ha revisado en su obra, muy dilatada, una y otra vez la idea aristotélica de ficción. En dos de sus libros recientes: Les bords de la fiction, de 2017 y Le fil perdu. Essai su la fiction moderne publicado en 2014, arriesga a definir con contundencia el concepto. Se sabe, dice en este último, que, desde Aristóteles, la ficción no es la invención de mundos imaginarios sino una estructura de racionalidad: un modo de presentación que vuelve las cosas, las situaciones y los acontecimientos perceptibles e inteligibles. La fórmula más simple y apretada diría que aquello que separa la ficción de la vida ordinaria es tener un comienzo, un medio y un fin. And yet, and yet...

4 Vista de esta forma, la ficción tendría que deslindarse de dos espacios que la cercan: por una parte, de la misma realidad, que le proporciona los insumos que la ficción elabora de acuerdo a una necesidad y un verosímil; y de otra, de las ciencias sociales, que apuntan a explicar la realidad, liberadas de los artificios de la ficción. Sobre el primer asunto, que nos acerca a la idea de que la ficción produce un orden que la realidad no tiene, no hay más remedio que acudir, una vez más, al comentario que realiza Borges en el archifamoso prólogo a La invención de Morel, de Bioy Casares. No encuentra Borges mejor elogio a la obra de su amigo que señalar en ella una lógica propia, un verosímil interno y sólido ("intrínseco rigor" los llama Borges) que impide el desorden asiático que la novela realista (¿francesa, rusa?) copia de la realidad. Borges advierte, entonces, que "la novela característica, "psicológica", propende a ser informe". Con su gracia peculiar Borges señala que "nadie es imposible" en la novela rusa, que esa libertad acaba por equivaler al desorden y que todo procede del alarde de la novela "realista" de disimular su carácter de artificio. "Imaginación razonada" llama Borges al procedimiento de Bioy en su novela, y resulta, a su criterio, una vía hacia la perfección. (89-91)

5 Rancière, no nos olvidamos de él, recuerda el brevísimo prólogo de Borges cuando, en Les bords de la fiction se detiene en "Los crímenes de la calle Morgue" de E.A. Poe y la 
fundación, el día de abril de 1841 en que apareció en una revista niuyorquina, del género policial. Sin embargo, este punto de partida que supondría el íncipit de un género y de un tipo de ficción -opuesto al de la disolución de la intriga en el arbitrario acontecer de la "realidad"- debería ser sometido a una doble inquisición.

La primera la señala el propio teórico francés cuando "descubre" que lo que leen Dupin y el personaje narrador en el diario sobre el doble asesinato de la calle Morgue no es lo que se leía habitualmente en las páginas de fait divers de los diarios Parísinos. Si la argumentación recurre a ideas como la gran ciudad, sus calles y laberintos, el crimen urbano y las técnicas de combate, el hecho elegido para fundar un género que emblematizará la literatura moderna es excepcional y hasta debería decirse único. Se podría, con algún grado de metáfora, hablar de un hápax, acontecimiento tal vez posible en el sistema, pero no en la norma y que se inscribe en esta como un modelo que contiene un gran poder, genital, de producir sentido. Creo recordar que Barthes utiliza el término hápax en el formidable estudio del cuento "La verdad sobre el caso del Sr. Valdemar". Quizá en este relato lo que se cuenta no sea inscribible en ninguna norma de índole realista y muestre, con mayor contundencia, un aspecto de la ficción que atañe tanto a la novela rusa como al relato gótico o al género policial ${ }^{1}$. El "suicida por felicidad" (Borges dixit), el muerto que acomete el escándalo lógico de decir "Estoy muerto", el orangután asesino, albergan y esconden el sentido último de los hechos, sus razones más íntimas. Largos anticipos científicos abren generalmente los cuentos de Poe. Pocas veces se advierte que antes de poner en escena a Dupin y el narrador leyendo el diario ha transcurrido una cuarta parte del cuento gastada en disquisiciones sobre los juegos lógicos, las formas de la inteligencia y otras lucubraciones sin las cuales el cuento policial no puede echarse a andar. En el cuento gótico se puede recurrir a un caso con detalles presuntamente médicos o a reflexiones tan largas que adquieren a veces la dimensión de un cuento: así sucede con "El demonio de la perversidad", teoría y prolegómeno a cuentos como "El gato negro", "El tonel de amontillado" y sobre todo "El corazón revelador". La ficción se formaría en la intersección de un hecho excepcional, único o imposible, la falsa explicación general y científica de su acontecer y una dimensión enterrada que nunca podremos explicar, a la que nunca llegaremos: el núcleo oscuro del cual emergen los sucesos del relato.

7 La segunda inquisición se desprende, en parte, de lo que acabamos de afirmar. No solo la ficción, en la creación literaria, mimetiza las zonas oscuras de la realidad. También lo hacen los discursos científicos los cuales tienen la misión de revelar la racionalidad última que explica el acontecer social. Sin embargo, los mecanismos de fetichización, de alienación que fueron desarrollados por los grandes gurús del pensamiento moderno: Marx y Freud, sobre todos, obligan a los discursos científicos a recurrir a procedimientos ficcionales, aquellos que proveen de un orden y un sentido a los más variados y dispersos acontecimientos. No es, entonces, extraño, que, de la misma manera como el simulacro científico sirve de pedestal a la ficción literaria, el orden de lo ficcional sea el soporte de otras formas de saber. Sí, como se analizaba clásicamente en Balzac, los hechos particulares ficcionados debían ser el correlato de las escondidas fuerzas sociales que los justificaban, era esperable que en algún momento se rompiera ese equilibrio y lo real intentara emerger, barriendo con los procedimientos de simbolización que tendían al enmascaramiento y al espectáculo². 


\section{La posficción, una alternativa}

8 No sé si fue George Steiner el primero en utilizar el concepto en su ensayo en homenaje al filósofo Ernst Bloch titulado "El género pitagórico". El artículo es de 1965, está incluido en el libro que Steiner publicó al año siguiente: Lenguaje y silencio, y vale la pena recordar su contenido como leve paliativo de su imprescindible lectura completa.

9 Steiner plantea que luego del apretado siglo que transcurrió de Balzac a Joyce la novela y su ambición de totalidad entró en crisis. Señala que el último intento fue La muerte de Virgilio de Hermann Broch, que quiso expresar "un único punto que se desvanece, el instante del paso a la muerte, de la momentánea transición a lo que no puede narrarse porque se encuentra situado a un ápice más allá del lenguaje" (2006: 101). A partir de allí el desolador "periodismo" que es nuestra existencia tomó protagonismo y minó nuestra capacidad imaginativa3. "Para competir como sea con las chillonas alternativas de la televisión y el cine, la fotografía y los fonógrafos" escribió Steiner, "la novela ha tenido que encontrar nuevas áreas de asombro emocional" utilizando los recursos que hasta entonces había explotado la "porquería-ficción": sadismo y erotismo. (102)

Lo que sucedió, entonces, a la era de la ficción fue una poética del documento que Steiner llamó “posficción” (104). Si bien Steiner, en 1965, no podía conocer el proceso que había recorrido Truman Capote antes de publicar, al año siguiente, A sangre fría, ni, presumimos, estaba enterado de los anticipos del testimonio en los escritores latinoamericanos, sí había leído y pudo citar un libro emblemático en este tema: Los hijos de Sánchez de Oscar Lewis. Trabajo de sociología y antropología, sirvió de modelo a un género híbrido que tendría en poco tiempo un desarrollo inusitado. Dice Steiner que Lewis consiguió presentar sus desgrabaciones magnetofónicas con el "orden acumulativo" de la novela. Tal como expresábamos más arriba, lo que "descubre" Lewis como antropólogo y que luego se expandirá al ámbito del periodismo (Steiner habla de "alto periodismo") es el principio ficcional que provee a la realidad de un orden que ella naturalmente no tiene; o, dicho de otra manera, que la única forma de expresar la realidad es organizándola en un proceso narrativo, así su materia sea tan dispersa como una serie de reportajes grabados a distintas personas.

11 Pero el ensayo de Steiner no se detiene en este hallazgo que llama "documental poético", una posibilidad de la narrativa posficcional que tendrá un pródigo futuro, así Steiner considere que se trata de un género poco significativo. Steiner quiere rescatar una línea escondida, abierta, aunque con pocos emergentes, y que se mueve por búsquedas de nuevas orientaciones de lenguaje o de sintaxis. En ella se cruzarían los límites de prosa y verso, documental e imaginario, voz narradora y diálogos de los personajes, rompiendo una vez más la estabilidad de los géneros, de los modos y del propio estatuto de la literatura. Pero, agregaríamos al razonamiento de Steiner: ¿de qué literatura?

12 De la del simulacro, podríamos contestar, la que mantiene la apariencia de la suficiencia del lenguaje. Según Steiner, una línea que remonta hasta Blake y llega a Wittgenstein y Broch, pasando por Kierkegaard, Nietzsche, Benjamin, línea experimental que resuelve llamar "género pitagórico", "lleva en su interior un potencial de silencio, la posibilidad reconocida de que la literatura puede ser insuficiente". (110). Broch, insiste Steiner, ha tocado ese punto en que ya es inútil la palabra: la muerte tiene otro lenguaje. El término "pitagórico" alude a la música y la 
matemática, a las meditaciones sobre el silencio y la muerte, pero sobre todo a un estadio presocrático que liga la literatura a un exorcismo del antiguo caos.

El final del ensayo de Steiner vuelve a su homenajeado Ernst Bloch. En la rareza de la obra de Bloch ve Steiner el vacío inicial, la alborada de un nuevo viaje de conocimiento.

\section{Hipótesis de trabajo}

14 El despliegue de una obra, sus reiteraciones y variables hacen posible imaginar una voluntad fantasmática que organiza, ordena y desordena, pero al fin construye la obra como una teleología: obra y autor simulan la existencia de un sistema que funciona de acuerdo a un fin.

15 Conocí la obra de Leandro Delgado (Montevideo, 1967) en la secuencia que sigue: casi al mismo tiempo leí, cuando aún permanecía inédita, partes de su tesis sobre el anarquismo rioplatense y su novela, recién publicada, Adiós Diomedes. Era el año 2005. En ese momento no establecí un correlato entre ambos trabajos. Luego debí haber leído sus columnas en dos medios de prensa: el semanario Brecha y el diario la diaria, pero, si lo hice, lo olvidé, obedeciendo al soporte en que se presentaban como textos perecederos. En 2010 leí los Cuentos de tripas corazón y en 2013 la novela Ur. Tiempo después Leandro me alcanzó un raro ejemplar de Alerta Naranja, cuentos publicados con la estética cartonera en 2014. En el 2017 volví a leer de manera completa su tesis doctoral, Anarquismo en el novecientos rioplatense, ahora publicada en libro. Para la confección de este ensayo el escritor me acercó un volumen, todavía en formación, de cuentos no editados, que aparecerá, tal vez, en el correr del 2019.

Recompuesta la trama, transitados estos años a través de su obra, un mapa de ruta de este trabajo sería el siguiente: partir del primer libro citado, mezcla de novela de aprendizaje y documento generacional; lanzar desde él dos hilos: uno hacia la tesis sobre los anarquistas, hecha en tiempos simultáneos con la novela, otro hacia los artículos periodísticos, que podrían entenderse como su consecuencia; leer la intersección, la zona de pasaje y las mutaciones que se producen entre la ficción narrativa y la periodística para ir descubriendo la configuración de una nueva estética que puede recurrir a un realismo catastrofista, expresionista y visionario y desplazarse hasta un campo de fantasías que incluye una ciencia ficción del pasado y del futuro. Si una zona de la obra de Delgado se deja leer como ficción (Adiós Diomedes), otra lo hace de acuerdo con la idea steineriana de "documental poético" (las crónicas urbanas) y en el otro extremo la novela Ur y buena parte de su narrativa breve podrían aspirar al "género pitagórico".

\section{Arlt: las cuatro estaciones}

17 Otra manera de recorrer la obra de Delgado sería plantearla en cuatro estaciones que tendrían como telón de fondo la obra de Roberto Arlt. Esta no oficiaría de modelo imitado por Delgado sino como arquitectura crítica, programa o plataforma epistemológica que hace posible una explicación del proceso narrativo del escritor uruguayo.

Primera estación. El punto de partida de la obra de Delgado sería similar al de Arlt: la novela de aprendizaje, de formación, de crecimiento. A la manera de El juguete rabioso, 
Adiós Diomedes propone una ficción bajo el modelo de la bildungsroman, con alguna diferencia no menor: su ubicación en un pasado marcado por señales históricas agrega al aprendizaje del héroe un sentido generacional que la novela de Arlt no exhibe con tanta evidencia. De esa manera se presenta como parte de la saga de novelas generacionales uruguayas que, desde fines de los noventa, buscaron explicar literariamente los años 80. Con esta intención se ubica La cura (1997) de Gabriel Peveroni, Arena de Lalo Barrubia (Rosario González), una novela publicada en 2003 pero seguramente escrita años antes y Papeles de un poseído de Julio Inverso, novela concluida hacia el final de su vida (Inverso se suicidó en 1999) y que recién se conoció en el año 2009. Los destiempos de publicación no hicieron más que reconocer el interés que estos escritores nacidos en los años 60 (Inverso en 1963, Lalo Barrubia y Delgado en 1967 y Gabriel Peveroni en 1969) tuvieron por ese período, los ochenta, que para ellos fue de formación; al mismo tiempo subrayaron la importancia que la década tuvo como muestrario de las posibilidades históricas del Uruguay de fin de siglo, a la salida de una dictadura de trece años y ante un futuro de difícil intelección. En este punto quizá sean mayores las distancias que las aproximaciones con la narrativa argentina. En dos de los narradores estrictamente contemporáneos de los uruguayos citados, Fabián Casas (1965) y Pablo Ramos (1967), podríamos encontrar un eco del modelo de formación. Sin embargo, creo percibir un énfasis distinto. Los narradores uruguayos presentan los personajes de sus relatos cumpliendo un proceso de aprendizaje mojonado por instancias políticas decisivas en la historia reciente del Uruguay: el plebiscito constitucional del año 80, los proyectos de democratización entre el 82 y el 84, el regreso de la democracia en el 85 , las razzias, la ley de impunidad militar en el 86 y su confirmación en el 89. Los argentinos parecen atender más bien al recorte y ubicación en el mapa social de esas figuras. ${ }^{4}$ En todos los casos, uruguayos y argentinos, son sospechables registros autobiográficos. Está claro que el niño de Los lemmings ("El bosque pulenta") y el joven de Ocio aparecen marcados, también, por el momento de los sucesos (la insistencia en el peronismo: "todo lo hizo Perón", durante los años de proscripción, el sonido de Spinetta o de Manal). También en el niño de El origen de la tristeza o en el hombre de La ley de la ferocidad pueden verse las señas del tiempo en el que viven. Pero los casos argentinos presumen elementos más intemporales impuestos por la relación (presencia y ausencia) con los padres ${ }^{5}$. En ese punto la novela de formación argentina seguiría con más fidelidad el modelo arltiano con sus ritos de iniciación en el delito, el sexo y la droga.

19 La segunda estación arltiana es la que hace la crónica de la ciudad rabiosa: manipulando la terminología de Josefina Ludmer podríamos hablar de realidadficción. Pensémoslo de esta manera: el modernismo, movimiento literario por excelencia (con esto refiero a su nítida noción de literatura, a su clara inscripción en la consecución de la belleza) tuvo notable producción de un género particular y anfibio como la crónica. La crónica se plantó en un territorio ambiguo de fuerte relación referencial con el objeto o asunto tratado y un cierto grado de desrealización conseguido mediante efectos de estilo, lenguaje, etc. Si se observa la modalidad particular de crónica de viaje, que modernistas como Martí, Darío y Rodó practicaron para los medios de prensa en los que trabajaron, se verá la aptitud del género en la circunstancia itinerante. A los escritores modernistas, cuya relación con la creación era parapetarse tras el texto (ser o proyectar lo subjetivo en el estilo), la crónica los proveyó de un campo de trabajo o de prácticas en el que se cruzaron distancias descriptivas con formas de la intimidad del tono de la carta o el diario personal. A fines de los veinte Arlt recogió la ya centenaria vinculación 
de la crónica con el periodismo para darle alguna originalidad. El flâneur baudeleriano de los pequeños poemas en prosa, pasado por Fray Mocho (José Sixto Álvarez) y Soiza Reilly, devino un personaje que es voz y andar errante y que produjo una relación con la realidad impregnada de registros anímicos. No es Arlt y sus aguafuertes el tema de este trabajo, pero habría que pararse una vez más en el estudio de las cualidades de observación y descripción que Arlt despliega (con altibajos en sus crónicas extranjeras o de viajes) y la deformación que éstas sufren cuando el motivo tratado es muy íntimo. Lo que puede interesarnos ahora es la relación anímica con lo exterior que en Arlt se produjo permanentemente y que ingenió títulos de períodos de sus aguafuertes como "la ciudad se queja". En las literaturas que Sarlo llamó etnográficas y Ludmer posautónomas o diaspóricas (en éxodo, afuera y adentro de la literatura y de la ficción), y que ambas críticas tipificaron en sendos ensayos hacia fines del 2006, se catalizó algo que ya podía aparecer como inminencia en las crónicas arltianas: la fabricación de presente con la realidad cotidiana. La diferencia entre el momento de Arlt y el que estamos estudiando en este ensayo puede ser el del carácter de esa realidad de la que la literatura se hace cargo. Es más evidente hoy que en los años 30 del siglo XX la realidad como puesta en escena, la sociedad del espectáculo. Y no es que Arlt no lo entendiese, pero en todo caso discriminaba los territorios y escindía de sus crónicas los efectos teatrales de la realidad, la existencia de una realidad imbuida de potenciales mágicos o fantasmáticos que guardaba para sus cuentos, novelas y dramaturgia. Esto constituirá el tercer andarivel del que hablaremos un poco más abajo.

En esta segunda estación, las decisiones literarias adoptadas por Leandro Delgado quizá aventajen, en su condición arltiana, a las de sus coetáneos argentinos. Delgado desprendió de su novela de aprendizaje y generacional (escrita fuera del país) ${ }^{6}$ sus propias crónicas urbanas (surgidas del choque con la realidad luego de su regreso) en series que fueron alejándose del documentalismo. Así lo insinuaron los títulos que eligió para ellas. La más nutrida que publicó en el semanario Brecha entre 2006 y 2009 tuvo un encabezamiento común de emblemática significación urbana: "Lomo de burro". Numerosas crónicas se hicieron cargo de circunstancias ciudadanas, aunque desde el principio, y con más asiduidad al final, el mero afán cronístico fuese intervenido por el imaginativo. Este territorio anfibio se adivinó mejor en la sección que Delgado mantuvo en el diario la diaria, poco después de clausurada su colaboración con el semanario Brecha. La columna de la diaria se llamó "Psicogeografías", virando o, mejor, ilustrando una estrategia que ya estaba presente en la anterior serie. Las últimas y espaciadas colaboraciones con la revista Lento, mensuario del mismo medio de prensa, ya le fueron solicitadas como cuentos.

21 Cuentos de tripas corazón, del 2010, reunió un conjunto de relatos inéditos que se cerraban con una crónica que había dado a conocer en una revista argentina. En Alerta naranja, del 2014, cuatro de los cuentos habían tenido versiones en la prensa, en la columna "Lomo de burro". Un "lomo de burro" abre la segunda parte de la novela Ur. Según el autor ha dicho, algunos pudieron ser cuentos que terminaron en la prensa, otros tuvieron su primera versión periodística para ser luego integrados a los libros. La precisión anterior contiene un comentario obvio: la distancia entre las crónicas que Delgado escribió para la prensa y sus relatos escritos como cuentos no parece ser grande y si unos difieren de otros Delgado está dispuesto a barajarlos y a dejar que los límites de cada género se corran y se acerquen. Si el lector tuviera la posibilidad de leer la columna periodística toda de corrido (por ahora eso es solo posible en la colección del medio de prensa en que salieron) encontraría que la mayoría de la treintena de 
artículos de "Lomo de burro" son comentarios sobre la ciudad, su vida, sus movimientos, su tránsito, la convivencia de seres y objetos. Pero, sin salirse del escenario urbano, algunos textos se desentienden de los acontecimientos inmediatos y atraviesan lo documental hacia la ficción.

Tercera estación arltiana. Una especulación: los cuentos y novelas de Delgado se fueron escribiendo al mismo tiempo que sus columnas periodísticas; por lo tanto, en cada territorio es visible la hibridación de recursos. La figura de autor que emerge de allí es la que aparece en el epígrafe de este ensayo: Delgado no se ve a sí mismo como un autor literario del tipo tradicional sino como un performer o un actor. La creación se correspondería pues con la fabricación de presente ya advertida, con la idea de que el escritor no está afuera del espectáculo de la realidad, sino que forma parte de él, lo informa con su trabajo. Así se leería la obra de Delgado en términos de realidadficción: como el descubrimiento de una realidad que no es la del realismo canónico sino la del mundo creado por los simulacros visuales, auditivos, producidos por las nuevas o no tan nuevas tecnologías. Su propia ficción es "la realidad". Las derivas de Delgado hacia la ciencia ficción estarían provocadas por las formas en que advierte la espectacularización de la sociedad y su correlato adverso, la falta absoluta de guion del espectáculo, de previsibilidad del futuro. La ciencia ficción de Delgado no es la de la clásica definición: proyección posible del presente sobre el futuro, imaginación controlada por las reglas del mundo actual. Más bien trata de fuerzas y poderes desatados, productores de fuertes anacronismos, que actúan sin ninguna previsión en un mundo posible. Así se puede leer Ur y también algunos cuentos publicados en los dos libros que se conocen hasta hoy. En un relato inédito, al que todavía no pudo dar su forma final, Delgado intenta una reflexión sobre el nudo que planteamos: un personajeartista, que es un ser humano afantasmado, produce visiones de futuro o, mejor, produce ese futuro con sus visiones poéticas. Como es poeta político ha anticipado la muerte de personajes políticos. Esa forma de intrusión del arte en la política se completa cuando el espíritu con sus visiones es absorbido, literalmente, por dos de los candidatos de las elecciones internas de uno de los partidos políticos uruguayos, pasando de uno a otro y actuando desde dentro de ellos (el cuento tiene el ambiguo título de "Elecciones internas"). Luego de una extensa y desgarbada historia que enfrenta a esos dos candidatos, el artista se aleja, se escapa con la conciencia de la bizarría absoluta de lo que sucedió como consecuencia de su participación. El relato se cierra con una poética de la rareza, que denuncia su incomprensión en el presente y su reconocimiento en un futuro posible.

Recapitulemos: a la reconstrucción, desde lejos, de la ciudad pasada que se va borrando (Adiós Diomedes), le sigue, en la obra de Delgado, la peripecia del paseante urbano que la arma en puro presente ("Lomo de burro"). Uno de sus rasgos dominantes es el rencor ante el progreso periférico, la rabia que le produce la modernización menesterosa. La experiencia de desesperanza y fracaso de la novela (a pesar de su lánguido o irónico final feliz) -distancia, nostalgia y melancolía del pasado- se convierte por actualización e inmediatez en furia y desazón, recalentamiento del presente ante una ciudad en la que crece el dolor. Sin duda se trata de dos modos de realismo con toques fuertemente expresionistas, heridos por una mirada que desgarra la realidad que ve. En ese sentido no parece lejos de la forma que utilizó Roberto Arlt y que Analía Capdevila denominó "paisajes emocionales", luego "realismo visionario", conceptos acuñados entre el 2004 y el 2006, en el cuadro de un debate sobre el realismo en la academia argentina. 
24 La pregunta que se hace el realismo visionario es cómo advertir el futuro contando el presente o que hay en el presente que se pueda leer fuera de sí, como algo que lo desborda. En Arlt (en Kafka, podría decirse también) se cuenta en presente. La presencia de un Comentador que es quien escribe la historia de Erdosain y los siete locos no postula la historia como pasado; es garante de la realidad de la ficción, aunque la extravagancia de lo que se cuenta y el contrato de veridicción exijan entender la historia como futura o como imposible. El poder sugestivo de la ficción, dice Analía Capdevila, supera al poder de inspiración de la realidad inmediata. Aunque la representación parezca representar cosas reales (referencial), representa otras imágenes o simulacros de realidad, según los términos utilizados por Hal Foster en El retorno de lo real. Pero a diferencia de las observaciones hechas sobre el pop como arte simulacral de pura superficie, la literatura de Arlt o de Kafka se las ingeniarían para evitar lo referencial sin perder la hondura simbólica. La profundidad referencial y la interioridad subjetiva provendrían de un sentido desplazado de los signos presentes que no perderían su estatus antropológico. Los desajustes temporales: juegos de presentes, más o menos puros, y pasados y futuros imaginados abrirían la noción, manejada por Julio Prieto, de "realismo mesiánico". La posición del español Julio Prieto corregiría con cuidado el trabajo pionero de Adolfo Prieto, el argentino, que aventuró una separación entre el "verismo desgarrador" de las novelas arltianas y su posterior ingreso a lo fantástico. Adolfo Prieto postulaba una gradación: de un realismo que excluía lo fantástico, del que el cronista primero no podía salir a pesar de las pulsiones interiores que se le revelaban, se pasaba a la fantasía, liberada en cuentos y obras de teatro. Julio Prieto prefiere subrayar la zona de fricción entre realidad y delirio para anticipar lo fantástico ya en las novelas de Arlt. El realismo mesiánico, dice Julio Prieto "es un modo de realismo que no excluye o reprime sino en cierto modo demanda y atrae la inscripción fantástica y la magia específica de una serie de actos de resurrección histórica y de los imaginarios de insurrección por ellos convocados" (2016: 72).

25 En este punto la obra de Leandro Delgado y de Pablo Ramos tendrían por el realismo el mismo irrespeto, desbordándolo y llevándolo a sus límites retóricos. Ellos y otros escritores de relatos que hemos llamado generacionales exacerban las experiencias colectivas: las drogas y el sexo ocupan un lugar dominante en estos relatos. Un procedimiento narrativo resulta de singular efectividad (Delgado no lo usa): el narrador en primera persona del plural que colectiviza la experiencia. Aparece en Mariana Enríquez ("La Virgen de la tosquera" en Los peligros de fumar en la cama) y lo usa Gonzalo Palermo en su novela aún inédita Después de la guerra contra los conejos (premio Onetti 2018) a la sombra explícita de Las vírgenes suicidas de Jeffrey Eugenides o como involuntario plagio-homenaje a la resonancia que dejó el nosotros onettiano en la literatura rioplatense.

Cuarta estación arltiana: la locura. Onetti (inventor de locos, sobre todo locas) decía envidiar de Arlt dos cuentos: "Las fieras" y "Ester Pimavera" y abominar del resto. No hay explicación y nos deja la oportunidad de una: "Ester Primavera" es un cuento "ruso", el cuento de la locura en Roberto Arlt. La locura es un tema en Arlt: la apelación a esa condición en los personajes de su novela central, su puesta en escena en los dos Saverios y en "La juerga de los polichinelas". Según Julio Prieto la clave en Arlt es poner la locura como límite, como borde(r) de la ficción, crear un espacio en el que el desarraigo, el absurdo del mundo (en Arlt la guerra constituía un sujeto privilegiado) 
asaltaba la literatura al tiempo que ésta se convertía en un plan de salvación real. Es fácil en Arlt complementar esta explicación del empeño literario con su par industrial, que se reúnen en la carta a su hija poco antes de su muerte: "Esta media durará por lo menos un año. Su transparencia es notable. Ponele un papel impreso detrás y podés leerlo". Como se sabe, el testimonio no es exacto. El invento de la malla para medias en el que Arlt había empeñado los últimos años de su vida fue un fracaso, por lo menos en su transparencia que era virtud fundamental, única, de la media de mujer. La hipotética lectura a través de la malla daba a la escritura una condición opaca.

En sus cuentos, Leandro Delgado aplica fórmulas de opacidad. No es la malla de látex de la realidad ni la fábrica de fosgeno de la ficción. Es la esquizofrenia verbal provocada por el máximo alejamiento: desaparición de todo tipo de narrador-autor y apelación al caos e interferencias de la realidad (si la realidad son los medios): "09002776"; o la máxima proximidad, el interior de sujeto psicótico que crea un mundo alternativo también construido a partir de las redes tecnológicas: "En la vida hay amores que nunca", tal vez su mejor cuento. Una fórmula intermedia es "Veinte minutos de terapia", un cuento que transforma un thriller en sesión analítica o al revés. El anarquista de principios del siglo XX, que escribe su periódico Destrucción en los textos titulados "Destrucción 1,2 y 3" del libro Alerta naranja, se pregunta si el abandono de la belleza por parte del arte (su entrega al experimentalismo, a la baudeleriana belleza negativa) no ha dejado al hombre sin una de sus riquezas, empobreciendo su experiencia.

En la instancia más avanzada de su narrativa, la obra de Delgado se hará cargo, de manera explícita, de su poética de la desnarratividad. Así se expresan los personajes de Delgado en dos de sus relatos inéditos:

Yo dejé de escribir porque me estaba dando cuenta de que empezaba a entender lo que estaba haciendo en ese delirio. Como que ese delirio empezó a adquirir un sentido. Una cara. Una forma reconocible. Empecé a encontrarle. Interpretaciones. No de aquello que los textos querían decir secretamente o no quisieron decir. A la manera de un crítico. Sino del sentido que tenían para mí. De lo que revelaban de mis mecanismos mentales. De mis formas de sublimar o de huir. Y yo no quería saber esa mecánica. Porque cuando llegara a entenderla me iba a aburrir mal. Me iba a decepcionar incluso. Ah. ¿Era esto? Y de esa forma se iba a romper la ilusión de que escribiendo era El One. Porque ya no podía descubrirme más. Como se descubre a OTRO escritor. [...] El asunto. Creo. Sería. (Volver a.) Contar algo siempre con una herramienta distinta y optando. Sin conflicto ninguno. Entre los caminos nuevos y los caminos conocidos en la medida en que no perdamos la sorpresa. Es decir. Sin buscar la misma sensación y tratando de llegar a otro nivel de emoción. De conmoción. De revelación. Cada vez y todo el tiempo. ("Culebrón erudito", inédito)

...porque todo debía ser ubicado supersticiosamente en cánones inútiles para hacer de mí una falsa leyenda en vida y, justamente, matarme en vida al escribir, al estímulo de una crítica débil, dispersa y persistente como la garúa, la anécdota lineal y verosímil que los tranquilizara a todos en parálisis pintorescas, la anécdota para desgranar -en un velorio a lo mejor- un rosario de identificaciones sobadas, de falsas erudiciones que sedaran a los esforzados imaginadores de poemas [...] Allí quería estar yo, allí debía estar, en la feria del domingo del futuro, en un libro encontrado por casualidad por alguien que no buscaba leerme (ni como autor ni personaje) porque yo había sido respetado por la indiferencia de mis contemporáneos, por su decencia de ignorarme y por dejar todas estas páginas en las ajadas, indómitas postrimerías. [...] Me alejaba de todas las expectativas alienígenas que buscaron anclarme con palabras reconocidas, con sintaxis agotadas... ("Elecciones internas", inédito). 
El discurso psicótico alberga una voluntad desnarrativa, destructora de las tramas argumentales. Entre los narradores rioplatenses de las últimas décadas se han presentado con cierta claridad dos impulsos: la modalidad desarticuladora que sintoniza la sintaxis con los sinsentidos, exteriores e interiores, que la literatura no puede ordenar del todo (el caso que estamos presentando, la prosa neurótica de Dani Umpi, Gabriela Cabezón Cámara) y el regreso a una narración que aspira casi al relato clásico de tensión, suspenso, enigma, aunque las respuestas no sean tan clásicas: para este tipo Mariana Enríquez es el mejor modelo. La presencia e influencia de César Aira, ya larguísimamente estudiada, fue y sigue siendo vital en este hacer y deshacer la narración.

\section{Un caso: Adiós Diomedes}

\section{Quilómetro cero}

La Onda cayó cansada contra el cordón hundido.

[...] La noche era negra, con remolinos de llovizna. [...] Había apagón. Todo el Centro y el Cordón estaban a oscuras (11).

El lector uruguayo y, sobre todo, montevideano, sabe que estamos en la plaza Libertad, en el quilómetro cero. El lugar donde comienza la primera novela de Leandro Delgado (estoy dejando en un limbo indefinido la página y media que precede a este comienzo y que está titulada "Al lector") queda aludido, prosopopeya mediante, por el nombre de la compañía de ómnibus que moró allí durante décadas hasta su cierre. Desembocadura y punto de partida, no pudo, mientras la compañía existió, dejar de ser un signo emblemático de un país que comenzaba o terminaba en su más extremo sur, en su capital y a escasas cuadras del mar ${ }^{7}$. Allí llega Diomedes, una noche imprecisa e inhóspita quién sabe de dónde:

No recuerdo -dice el personaje-narrador de la novela- si Diomedes me contó toda esta escena o yo la imaginé. Pero es como si me la hubiera contado él. Si pienso en Diomedes, siempre lo veo bajar dormido de esa Onda en una noche de apagón llegando a Montevideo. [...] Será porque Diomedes nunca me dijo de dónde venía que yo le inventé un origen, una llovizna y un apagón (12).

La llegada a la ciudad, esa noche llena de señales y de augurios, está seguida, en las primeras páginas de la novela, por el lugar en el que el protagonista-narrador de la novela conoce a Diomedes. Sobre el primer episodio digamos alguna cosa más. Una esfumada cronología, pautada por hechos, lugares y algún año preciso (1984) sugiere que la llegada de Diomedes se produce hacia 1980, en algún momento de principios de esa década. Pero así no hubiese ninguna observación temporal que nos guiara, el halo que cubre o encubre los acontecimientos se corresponde con el clima ominoso del Uruguay de esos años. La novela disuelve el documentalismo (y ya veremos enseguida cuál puede ser su poética en este sentido) gracias a una fuga constante de los hechos que, se insiste una y otra vez, son partos de un presente que los rehace -los actualiza sería más exacto- bajo el continuo malentendido de una cierta nostalgia. Una de las causas, la más epitelial, de esa nostalgia puede ser producida por la desaparición de la compañía de ómnibus con la que Diomedes llega a nuestra historia y que cerró sus puertas más de diez años antes de la fecha en que la novela cierra las suyas, 5 de julio de 2003. 
De la evocación con que se abre Adiós Diomedes no surge nada glamoroso: los lugares y los hechos emblemáticos están sumergidos en la penumbra de un tiempo siniestro que, en consonancia, se imagina nocturno, lluvioso y con apagón. Por cierto, la novela prodigará en su desarrollo detalles que indiquen los mentados años 80 como momento de su acontecer. Más adelante comentaremos cómo y en qué medida esta novela se sostiene en cierta teoría sobre esa década, que el autor ha hecho explícita y que tuvo que ver con su actividad académica: el estudio sobre los anarquistas rioplatenses del 900. Pero no adelantemos todavía este tema Mantengamos nuestra atención sobre los dos primeros lugares que la novela explana: a escasas cuadras del quilómetro cero en el que la novela arranca, se encuentra el bar donde trabajaba Diomedes y en el que el narrador lo vio por primera vez.

\section{Dibujos en un espejo}

La escena toma el cariz de una poética. Remite a otra escena inicial, la que Cortázar ideó para 62 modelo para armar, sin las complejidades del juego de reflejos y palabras, traducciones y citas que pone a funcionar la novela del argentino. Para entender nuestro caso reproduzcamos el fragmento:

En toda la pared detrás del mostrador había un espejo donde estaban pintadas, por mano hábil, las delicias que alguna vez la casa había ofrecido a una clientela desaparecida. Cada dibujo estaba acompañado de una pequeña leyenda fileteada. Los churros estaban hechos de un solo trazo marrón claro con unas estrías más oscuras encima, de pincelada seca, que le daban el efecto poroso, azucarado. Detrás había una taza humeando, muy de perfil. El vapor del chocolate era apenas dos líneas ascendentes, como la vela de un barco, ancha abajo y afinándose en un triángulo que empezaba a oscilar. Había algunos dibujos y leyendas. Pero lo único relevante, porque representa para mí, la conciliación definitiva de todos esos recuerdos dispersos, era el dibujo del chocolate con churros. Cada vez que evoco ese dibujo pintado sobre el espejo, la imagen de Diomedes fregando el mostrador aparece reflejada detrás, algo fuera de foco. Hay una razón preceptiva para la fuerza de ese recuerdo original, que es la superposición de dos imágenes sobre la superficie del espejo. También hay otra más rebuscada, más improbable, pero cargada, creo yo, de más significados (13-14).

Con una fidelidad un poco rastrera diríamos que el pasado se representa en un dibujo estilizado sobre un espejo. La simplificación desrealiza la imagen y la separa del hoy haciendo inasible, inalcanzable su referencia: el chocolate con churros. Que esta imagen del pasado sea recuperada sobre un espejo permite una doble intrusión del presente: la explícita de Diomedes detrás de los dibujos fregando el mostrador, y la sorda del propio narrador que habitaría en el espejo el lugar reflejo del punto de vista. La desaparición, en el tiempo presente, del chocolate con churros, la pura evocación nostálgica en el dibujo del espejo, porta consigo el sentimiento nacido del "vestigio de un tiempo muerto y sepultado". La historia de Diomedes emblematiza, en pasado y presente, lo que se sabe y lo que no, lo que quedó sepultado "en el silencio de una vida anterior sobre la que nunca quiso hablar".

En la descripción sucinta de Diomedes fregando parece aflorar cierta nostalgia, pero es algo completamente involuntario, un malentendido del presente. [...] Toda esa decadencia prematura que respiraba el boliche, ese olor rancio y dulce desde que se cruzaba la puerta, todas las moscas muertas entre las pastillas Trineo al lado de la caja, el trapo de piso negro al lado del baño y hasta los mismos dibujos del espejo, 
ocres por el humo del cigarrillo, todo eso, lo invade una melancolía que no puedo controlar, injusta en su persistencia (14). mapa de sentido. Trato de imaginarme, para dar claves de lectura y evitar fatigosas descripciones del argumento, algún juego de mesa que me proporcione una parábola más o menos certera de la novela, pensándola como una bildungsroman, novela de aprendizaje o de formación o de crecimiento (ya volveré a esta aproximación). Sería un juego ajeno a la habitual lógica de un manual de instrucciones y sometido al orden asiático con que se presenta la realidad. Así, en un damero clásico en el que los casilleros blancos y negros tuviesen un valor simbólico, las piezas se irían moviendo y trazando itinerarios imprevisibles que alternarían unos y otros. Una primera impresión marcaría el carácter solar, así sea de sol negro, en los personajes masculinos, y un orden nocturno, de potencialidad lunar en los femeninos. Sin embargo, ese esquema no sería inalterable si pensamos que de lo más hondo del casillero negro de la droga (y me hago cargo de mi evaluación negativa, aunque creo que la novela me da amplia autorización) Alicia saca al narrador y este, al final, sacará a Tamara. Dos figuras paternas tienen como pivote al narrador: Diomedes y su propio padre. Diomedes es el personaje metamorfoseante, que cambia de aspecto y hasta de nombre; es, tal vez, el que muestra más explícitamente las marcas y las abolladuras del choque con la historia. Militante estudiantil a principio de los ochenta, artesano en la emblemática Feria de Libros y Grabados en 1984, mezcla de neohippie y trabajador independiente en Solymar, músico en los primeros años de democracia, Diomedes protagoniza, con luces y sombras, la primera de las cuatro partes de la novela. En la segunda, Diomedes es sustituido por el padre del narrador. Como corresponde a este nuevo protagonismo, el de un padre ganado por el desconcierto, es el período del consumo y las malas compañías y el de la visita al COMCAR, el mayor centro penitenciario del país. En el momento en que el padre encuentre un camino para su vida reaparecerá Diomedes ahora convertido en Juan de Dios, líder musical de un conjunto de rock punk llamado Dios A Muerto. Se abre la tercera parte de la novela, la más claramente generacional. Estamos en un barrio de Montevideo en el que forman nudo los distintos hilos desplegados hasta ahora: la movida callejera, las revistas under, un autorreportaje de Diomedes que define los principios ácratas del período, los efluvios carcelarios que llegan y producen un nuevo choque de culturas9. La parte cuarta es la de las precipitaciones: muerte del padre, rechazo de la propia paternidad del protagonista $y$, en su defecto, ocupación del lugar y la tarea que su padre había iniciado. Parte de cierre: la aparición final de Diomedes es la escena de la locura. Diomedes encarna la paranoia en un episodio violento que lo hace desaparecer. Luego de contar la desaparición de Diomedes detrás de la locura, el último capítulo titulado "Hoy", produce una anagnórisis: la imprecisa foto de un grupo de rock en una enciclopedia, remontaría la historia hasta el origen borrado. No se sabe el futuro y algo se adivina del pasado. Diomedes resume con todos los matices una historia que siempre estaremos reconstruyendo.

\section{Los pretextos de la escritura}

36 El relato pendula entre tiempos y lugares. En el orden más lejano -el pasado de la historia- Montevideo es la ciudad a la que llega Diomedes desde un lugar anterior e impreciso, tal vez muy cercano, del interior del Uruguay, y es la que lo expulsa a un 
balneario, Solymar, también muy próximo geográficamente. Es la ciudad que tiene el centro penitenciario más grande del país, ubicado en uno de sus extremos topográficos, pero que socialmente no está tan descentrado. Diomedes cae en la ciudad de los ochenta, visiblemente afectada por la oscuridad. Viene de un interior del país del que se habla menos y que, para este caso particular, es el origen misterioso del personaje ${ }^{10}$. En el orden más próximo, presente de la escritura, espacio de la memoria recuperada fuera del país, el prólogo "Al lector" justifica la necesidad de "escribir a Diomedes" porque se le está borrando. Cuánto se podría jugar con el nombre de la banda musical en la que toca Diomedes, ya transformado en Juan de Dios: Dios A Muerto. Falsa afasia cuya borradura ¿agrafia? no cambia el sonido de lo que se pronuncia, pero cuestiona la frase inspiradora. La A mayúscula parece desprendida del círculo que la contiene en los grafitis de la anarquía. Este introito explica el vínculo entre vivir y escribir.

Un arco se tensa entre los dos marcos de la novela: como clausura, ese fuera del país señalado en el lugar y la fecha en que el libro fue concluido (N.Y. City, 5 de julio de 2003); en su comienzo, ese dentro del autor consignado en la dedicatoria que abre el libro: "A la memoria de mi padre". Los dos resultan difíciles de definir, los dos trabajan la ficción desde afuera; aluden, ambos, a la confusión entre vida y escritura. La dedicatoria, primera frase que se lee y tal vez última en ser escrita, refiere a la muerte del padre del autor. Anterior a la fecha consignada al final de la novela -el padre de Leandro Delgado murió en diciembre de 2002- el paratexto actúa como pretexto para la escritura. Se dedica y se escribe contra la muerte, contra el olvido. Cuando el texto se termina, y se data en julio del 2003, la escritura ha consumado un rescate.

\section{Cuentas pendientes}

En una apretada síntesis final esbozaré temas prometidos. Uno de los que asomaron al principio fue el de la vinculación de la primera novela Adiós Diomedes, con la tesis doctoral sobre el anarquismo rioplatense que Delgado escribió al mismo tiempo. Creo que el asunto generacional de la novela y el tema del anarquismo pueden presentarse haciendo sistema con otros que los acompañan.

Como se ha visto, el telón de fondo de la novela es la década del 80, un período signado por la cultura punk. El punk uruguayo, que floreció hacia mediados de esa década, y que tuvo una fuerte inserción juvenil, alentó en algunos críticos de la cultura (Luis Bravo en varias oportunidades) la idea de ligar la contracultura de los 80 con las neovanguardias de los años 60. El mismo Leandro Delgado, en sus trabajos y comentarios sobre la década, dejó pendiente una pesquisa que fuera más allá y rastreara elementos de un primer anarquismo, el del novecientos, en los jóvenes rockeros uruguayos de la salida de la dictadura.

40 La movida rockera, con su toque punk, sumaba a su aire libertario una pronunciación de índole neorromántica. En cierta concepción, el pasado nos dejaba sin futuro: la clásica antropología romántica que apelaba a lo gótico, al pasado de las ruinas que se levantaba como obstáculo del progreso de la historia, tenía un correlato en el grito "no future" que aullaba la cultura punk.

41 El autorreportaje al que Diomedes se somete en la novela contiene muchos de los postulados de una estética y una poética que pueden remontarse tanto a los años 60 como a los principios ácratas de los artistas en los albores del siglo XX. Frases como "el 
artista solo es bueno si es honesto" o "renuncio a la profesionalización, ese cáncer disfrazado de médico" pronunciadas por el personaje de la novela, remiten a las muchas intervenciones de los rockeros punk de los $80^{11} \mathrm{y}$ sesgadamente a las letras de sus canciones (otra investigación pendiente). "Mi mensaje solo expresa la verdad, mi mensaje ES verdad" dice sin hesitar Diomedes, en controversia con el nihilismo que supo impregnar el movimiento punk. "Hago el esfuerzo, día tras día, de no identificarme ni siquiera conmigo mismo. Cambio todo el día de opinión porque SOY la contradicción". Diomedes explana un programa según el cual los artistas pueden cambiar el mundo a partir de una entrega absoluta, una honestidad sin pausa y rompiendo con el concepto de autor que implica la propiedad privada del arte, su sometimiento al mercado de bienes económicos. "Hay que copiar, hay que deformar".

La diferencia más apreciable entre las respuestas ácratas, antiinstitucionales o contraculturales a lo largo del siglo XX es que en los anarquistas del $900 \mathrm{y}$ en la actitud antisistémica de los 60 había un programa futuro, un planteo porvenirista que no aparece en el desencantado movimiento punk. De allí que irrumpan, en el terreno de la creación simbólica en años recientes, dos asuntos a tomar en cuenta: el tema del padre, de los padres como figuras de referencia, y los modos de fantasía, en particular la ciencia ficción.

El conflicto con el padre (entre Hamlet y Levrero "La ansiedad de bastardía", señala Amir Hamed, 2014), con los padres, con la familia ha sido un lugar común de la narrativa más reciente. Todos los escritores que hemos citado en este trabajo han hecho algo con ese agujero complejo que son las relaciones filiales. Es habitual que a Samanta Schweblin le pregunten cómo es su trama familiar, siempre presente en sus relatos. Por cierto, también se lee el conflicto en relatos de Carlos Reherman, Pablo Ramos, Daniel Mella, Horacio Cavallo, Manuel Soriano, etc. En Adiós Diomedes el padre del protagonista parece salvarse de la quema y si bien es sucedido por su hijo no le trasmite su deseo de ser padre. El mundo de la violencia está muy vinculado con las figuras paternas (el robo en Silvio Astier como rito de iniciación y pasaje) y, como agregado, el de la droga.

Más difícil es relacionar esta trama con un modo de la fantasía: la ciencia ficción. El falso prólogo que Delgado titula "Al lector peninsular", incluido en Cuentos de tripas corazón, es un texto político. Lo es en dos sentidos complementarios: cuenta la peripecia del autor ficticio, que prologa sus propios cuentos de ciencia ficción, exiliado uruguayo en España, con su padre anarquista desaparecido en Argentina en 1976. Al mismo tiempo es una apología del género de ciencia ficción, a través del cual, dice el escritor, pudo reconstruir el mundo de su infancia. En homenaje a la ciencia ficción y en particular a la revista argentina El péndulo Delgado escribe:

En definitiva, este es uno de los preceptos más profundamente humanistas que tiene la ciencia ficción en toda su proyección ética y moral, es decir, la existencia de un mundo sin divisiones donde los seres humanos se unen, precisamente, por su humanidad. Por esta razón, la humanidad puede encontrarse en los rincones más apartados del universo desde que constituye la producción más sofisticada del cosmos, por lo cual puede surgir en cualquier parte, en cualquier momento y en cualquier escala del Infinito Todo. (29)

Esa condición humanista se compadece con el internacionalismo de la ciencia ficción, un aspecto que remite al narrador a la figura borrosa del padre desaparecido, con su anarquismo pleno de curiosidad por un mundo a conocer y con su terca confianza en el género humano. Ausente el padre, es la ciencia ficción quien acerca y familiariza un 
mundo cada vez más lejano, con ese paradójico alejarse y entrar en lo desconocido sin temor a perderse, porque el hombre es "como un astronauta que sale a caminar por el espacio sin perder contacto con la nave" (29).

\section{BIBLIOGRAPHY}

Benjamin Walter, “Tres iluminaciones sobre Julien Green” en Imaginación y sociedad. Iluminaciones 1, Madrid, Taurus, 1980, p. 105-123.

Borges Jorge L., "Prólogo" a La invención de Morel de Adolfo Bioy Casares, Madrid, Cátedra, 1982.

Capdevila Analía, “Arlt: por un realismo visionario", el interpretador "realismos 5”, número 27: junio 2006, Web. Consultado el 1/12/18.

Delgado Leandro (2005), Adiós Diomedes, Montevideo, ediciones planetarias.

--- (2010), Cuentos de tripas corazón, Montevideo, Estuario.

--- (2013), Ur, Montevideo, Hum.

--- (2014), Alerta naranja, Montevideo, la propia cartonera.

--- (2017), Anarquismo en el novecientos rioplatense. Cultura, literatura y escritura, Montevideo, Estuario.

---- (s/f), Elecciones internas, inédito.

Espinosa Gustavo, Las arañas de Marte, Montevideo, Hum, 2011.

Foster Hal, El retorno de lo real. La vanguardia a finales de siglo, Madrid, Akal, 2001.

Gutiérrez Girardot Rafael, Ensayos sobre Alfonso Reyes y Pedro Henríquez Ureña, México, El Colegio de México, 2014.

Hamed Amir, "La ansiedad de bastardía: muestra de narrativa joven uruguaya”, Hispamérica, año XLIII, 127, 2014, p. 67-72.

Ludmer Josefina, Aquí América Latina. Una especulación, Buenos Aires, Eterna Cadencia, 2010.

Prieto Julio, La escritura errante. Ilegibilidad y políticas del estilo en Latinoamérica, Frankfurt, Iberoamericana-Vervuert, 2016.

Rancière Jacques (2014), Le fil perdu. Essai sur la fiction moderne, París, La fabrique.

--- (2017), Les bords de la fiction, París, Seuil.

Reyes Alfonso, El deslinde en Obras completas de Alfonso Reyes, Tomo XV, México, FCE, 1963.

Rodríguez Mauricio, En la noche. El rock uruguayo posdictadura (1982/1989), Montevideo, Fin de Siglo, 2012.

Sarlo Beatriz, "La novela después de la historia. Sujetos y tecnologías" en Escritos sobre literatura argentina, Buenos Aires, Siglo XXI, 2007, p. 471-482.

Steiner George, “El género pitagórico”, en Lenguaje y silencio, Barcelona, Gedisa, 2006, p. 99-112. 


\section{NOTES}

1. Insisto en no diferenciar los relatos por la circunstancia de que lo que se cuenta pueda o no suceder en la realidad, en nuestra realidad, principio de las retóricas que estudian con minuciosidad sistemática los modos realistas, fantásticos, maravillosos y de otras índoles. La literatura es el lugar donde todo es posible y lo que interesa, me parece, es advertir lo que más arriba llamábamos el "sentido humano" de lo que se escribe. Este está, en general, escondido, ya sea tras el argumento realista como tras el no realista. Y lo que importa no es descubrir que alguien no puede, en el verosímil realista, despertarse un día, después de un sueño inquieto, convertido en un horrible insecto, sino cómo es que ese hecho tan peculiar permite de todas maneras que los otros personajes que no han sufrido esa transformación puedan hablarle al bicho, y cómo nosotros, personajes-lectores, podamos interesarnos por tan bizarra aventura sin tirar, después del primer párrafo, el libro por la ventana.

2. Ver el capítulo "El retorno de lo real" en el libro homónimo de Hal Foster.

3. En 1965 Steiner habló de "ficción verdadera" (2006: 103) para referirse a la forma en que las revistas de gran tirada presentaban, para su mejor venta, invenciones imposibles. Una reciente serie televisiva, Fargo (2014-2017), en la larga tradición de "basado en hechos reales", insiste, capítulo a capítulo, temporada a temporada, en advertir: "Esta es una historia real. Los hechos mostrados sucedieron en Minnesota en (va ajustando el año según la temporada, pero siempre es una fecha cercana). Por solicitud de los sobrevivientes se cambiaron los nombres. Por respeto a los difuntos, el resto se relata tal como ocurrió". Un juego mucho más complejo resulta del muy reciente libro de Jorge Volpi, ganador del premio Alfaguara 2018, que él llama "novela sin ficción" y titula capciosamente Una novela criminal. Los hechos son ciertos, el libro sigue una documentación rigurosa, pero al inevitable proceso de ficcionalización exigido para su presentación se agrega la "novela" inventada por el Estado mexicano (su policía) para hacer verdad mediática un crimen que no fue. Esa pirueta parece contener todos los componentes de este asunto que estamos desarrollando.

4. Una observación atenta a ciertos lugares comunes y necesitada de demostración nos dice que mientras la narrativa uruguaya precisa ordenarse según mojones históricos la argentina trabaja sobre un campo histórico convertido en mitos. Esto postularía una condición uruguaya más “documental" y una argentina más proclive a la lectura psicoanalítica. Pero bien puede suceder lo contrario.

5. Las novelas del uruguayo Daniel Mella responderían a este modelo argentino.

6. El año, 2003, y el lugar, New York City, que cierran la novela, dicen algo sobre su escritura. Delgado se había ido de Uruguay en 1999 y luego de una estadía en Reino Unido se instaló en Nueva York. Allí completó sus estudios hasta que en el año 2005 regresó a su país. La primera evidencia, entonces, es que Adiós Diomedes fue escrita fuera del Uruguay.

7. No es casual, entonces, que en la novela Las arañas de Marte (2011) del escritor treintaitresino (el departamento de Treinta y Tres está al este del Uruguay) Gustavo Espinosa la presencia de la ONDA cumpla un doble rol importante: es el medio en el que el protagonista escapa de la represión militar durante la dictadura, hacia Montevideo, y es la empresa en la que trabajó su padre, cuyos derrumbes son puestos en correlato: “... mi viejo se había estado muriendo durante años desde lo de la bancarrota de la ONDA" (147).

8. En uno de los artículos sobre la obra de Julien Green, Benjamin (1980) acuña el concepto de "presentización". Si no lo entiendo mal (siempre es posible entender mal a Benjamin) se trata, en los relatos de Green, de un extraño procedimiento según el cual los personajes no son presentados en un momento de su desarrollo del que alguien de afuera podría dar cuenta, sino como la inexplicable e imprevisible actitud de quien contiene en cada instante todo su futuro. Benjamin hace una rápida alusión a la figura de Dante llena de destino, que reproduce, en la repetición de una instancia vivida en la tierra, su existencia irrevocable tras el juicio final, 
instancia futura del plan divino. No creo que pueda aplicarse la idea medieval de figura a la novela que estamos comentando, ni si es eso exactamente lo que informa a los personajes de Green. Pero el concepto de presentización podría explicar los estados diferentes del personaje de Diomedes y sus transformaciones, metamorfosis que lo pone una y otra vez en un grado cero, un punto de partida de su existencia que se postula como episodio visionario. Por un lado, el misterio del pasado, mal revelado al final; por otro, los vaivenes de la historia a los que el personaje de Diomedes es especialmente sensible, explicarían sus virajes sin que un determinismo los haga previsibles.

9. Creo que cabe una nueva comparación con la novela de Espinosa Las arañas de Marte. El ingreso de la cultura popular y, por lo tanto, de una convivencia de culturas (alta, baja o como quiera calificárselas) se hace de distinta forma en las dos novelas. Mientras Delgado remite a la fusión entre rock y música tropical, netamente urbana, Espinosa despliega en su novela la cultura popular en la picaresca de tablado con rasgos pueblerinos.

10. En tiempos y destiempos, entre numerosos libros de testimonios, la literatura se ha hecho cargo de los aspectos ominosos en geografías no capitalinas: en 1987 Mario Delgado Aparaín con La balada de Johnny Sosa y en 2011 Gustavo Espinosa con la ya citada Las arañas de Marte publicaron dos obras importantes que calaron en el tenor de la represión y la resistencia en el interior. Mario Delgado lo hizo en sus regiones imaginarias, Espinosa desplegando la ficción en topografías que toman sus nombres de la realidad. También recrean espacios no capitalinos escritores como Damián González Bertolino, Valentín Trujillo, Pedro Peña, etc.

11. Entre los muchos reportajes a los rockeros de los ochenta, remito al que Mauricio Rodríguez le hace a Juan Casanova (Los Traidores, Peyote Asesino), uno de los protagonistas más elocuentes, para un libro publicado en 2012. El recorrido vital y de ideas de Casanova coincide en muchos puntos con el del personaje de la novela de Delgado. Nacido en los años sesenta, Casanova vivió la violencia política del país en ese período, mientras oía el canto de protesta y el rock de esa década. Formado como niño y adolescente en dictadura, encontró en el movimiento punk inglés una vía de escape a las instituciones autoritarias, un ansia de libertad. Esta libertad, como posible respuesta a la educación formal, suponía una idea radical del artista y la creación artística, tanto porque exigía una entrega absoluta como porque se desentendía de todo cálculo estético, político o económico y buscaba lo que estaba dentro de uno mismo sin técnicas ni aprendizajes. Al mundo oscuro de la censura y la represión, el punk opuso otra oscuridad: la del "no future" ("la percepción que yo tenía en ese momento -dice Casanova veinticinco años después- es que me iba a morir a los veinte años"), la de la "vida de mierda" plena de frustraciones y fracasos, la del espectáculo del dolor, también la de la droga. Al mismo tiempo no estaba excluido de su "programa" proponer ideas o "meter huevos para adelante para una vida mejor". Para una idea cabal vale la pena leer el reportaje completo (Rodríguez, 2012).

\section{ABSTRACTS}

Starting from the concept of "post-fiction", as George Steiner puts it in his essay "The Pythagorean genre" (1965), the fiction (Rancière) and its edges are reviewed, to be applied to the work of the Uruguayan writer Leandro Delgado (1967). Delgado's work will be studied in relation to other Uruguayan and Argentine writers who have published since 2000. The goal is to suggest 
a journey in which the forms of writing (narrativity, disnarrativity), some subjets and methods will raise similarities and differences. Roberto Arlt, his work, will serve as an epistemological platform for this study.

A partir del concepto de "posficción", tal como lo expone George Steiner en su ensayo "El género pitagórico" (1965), se revisa el de ficción (Rancière) y sus bordes, para aplicarlos a la obra del escritor uruguayo Leandro Delgado (1967). Se pondrá, en forma acotada, la obra de Delgado en comunicación con la de otros escritores uruguayos y argentinos que han publicado a partir del año 2000, para insinuar un recorrido en el que las formas de la escritura (narratividad, desnarratividad) y algunos temas y modos planteen parecidos y diferencias de familia. Roberto Arlt, su obra, servirá como plataforma epistemológica de este estudio.

A partir du concept de postfiction (de George Steiner dans son essai "Le genre pythagoricien", 1965), le concept de fiction (Rancière) et ses limites sont interrogés pour étudier l'œuvre de l'écrivain uruguayen Leandro Delgado (1967). On mettra l'œuvre de Delgado en relation d'autres écrivains uruguayens et argentins publiés depuis 2000, afin de suggérer un parcours dans lequel les formes d'écriture (narrativité, dénarrativité), tout comme certains sujets et des modalités posent des similitudes et des différences. Roberto Arlt, son œuvre, servira de plateforme épistémologique pour cette étude.

\section{INDEX}

Palabras claves: Ficción, posficción, desnarratividad, bildungsroman, novela generacional. Mots-clés: Fiction, postfiction, dénarrativité, bildungsroman, roman de génération

Keywords: Fiction, posfiction, disnarrativity, bildungsroman, generational novel

\section{AUTHOR}

\section{OSCAR BRANDO}

Facultad de la Cultura, Claeh

obrandoaramuni@gmail.com 